\title{
Evolution of Ion-Ion Interactions and Structures in Smectic Ionic Liquid Crystals
}

Seo Kyung Park, ${ }^{\dagger, \perp}$ Kee Sung Han, ${ }^{\ddagger, \pi, \perp}$ Jin Hong Lee, " Vijayakumar Murugesan, ${ }^{\ddagger, \pi}$ Seung Hyun Lee, ${ }^{\dagger}$ Chong Min Koo, ${ }^{\S}$ Je Seung Lee, ${ }^{*}{ }^{\dagger}$ and Karl T. Mueller*,‡,ף

${ }^{\dagger}$ Department of Chemistry and Research Institute of Basic Sciences, Kyung Hee University, 26 Kyungheedae-ro, Dongdaemun-gu, Seoul 02447, Republic of Korea

‡Physical and Computational Sciences Directorate, Pacific Northwest National Laboratory, Richland, WA 99352, United States

IJoint Center for Energy Storage Research (JCESR), Lemont, Illinois 60439, United States

"Department of Organic Material Science and Engineering, Pusan National University, Busan 46241, Republic of Korea

§Materials Architecturing Research Center, Korea Institute of Science and Technology, Seoul 02792, Republic of Korea

Table S1. Pore size of $a$ and the pore distance (cluster size) of $b$ between the hetero-structure formed by addition of LiTFSI to [DMIm][MPEG $200 \mathrm{Pi}$ ] and the effective diffusion coefficient, $D_{\text {eff }}$ obtained using eq 1 from ${ }^{7} \mathrm{Li}$ PFG-NMR echo profiles for samples of $\mathrm{x}=0.5$ and 1 .

\begin{tabular}{|c|c|c|c|c|c|c|}
\hline \multicolumn{7}{|l|}{$x=1$} \\
\hline$T(\mathrm{~K})$ & $a(\mu m)$ & $b(\mu m)$ & $b=q^{-1}(\mu m)$ & $\xi(\mu m)$ & $D_{\text {eff }}\left(\mathrm{m}^{2} / \mathrm{s}\right)$ & $D\left(\mathrm{~m}^{2} / \mathrm{s}\right)$ \\
\hline 263 & 1.2 & 4.4 & 5.4 & 0.01 & $7.4 \times 10^{-9}$ & $3.2 \times 10^{-12}$ \\
\hline 283 & 1.2 & 3.2 & 3.2 & 0.01 & $2.0 \times 10^{-9}$ & $2.5 \times 10^{-12}$ \\
\hline 293 & 1.4 & 1.5 & - & 0.01 & $4.6 \times 10^{-9}$ & $4.0 \times 10^{-12}$ \\
\hline 313 & 2.0 & 1.7 & - & 0.02 & $5.3 \times 10^{-9}$ & $9.0 \times 10^{-12}$ \\
\hline 333 & 2.7 & 2.5 & - & 0.02 & $2.0 \times 10^{-8}$ & $1.9 \times 10^{-11}$ \\
\hline \multicolumn{7}{|l|}{$x=0.5$} \\
\hline 293 & 1.3 & 1.9 & 2.7 & 0.01 & $9.0 \times 10^{-9}$ & $7.0 \times 10^{-12}$ \\
\hline 313 & 1.7 & 1.5 & 2.1 & 0.01 & $6.8 \times 10^{-8}$ & $1.0 \times 10^{-11}$ \\
\hline 333 & 2.1 & 1.7 & 2.8 & 1 & $1.8 \times 10^{-8}$ & $1.5 \times 10^{-11}$ \\
\hline
\end{tabular}




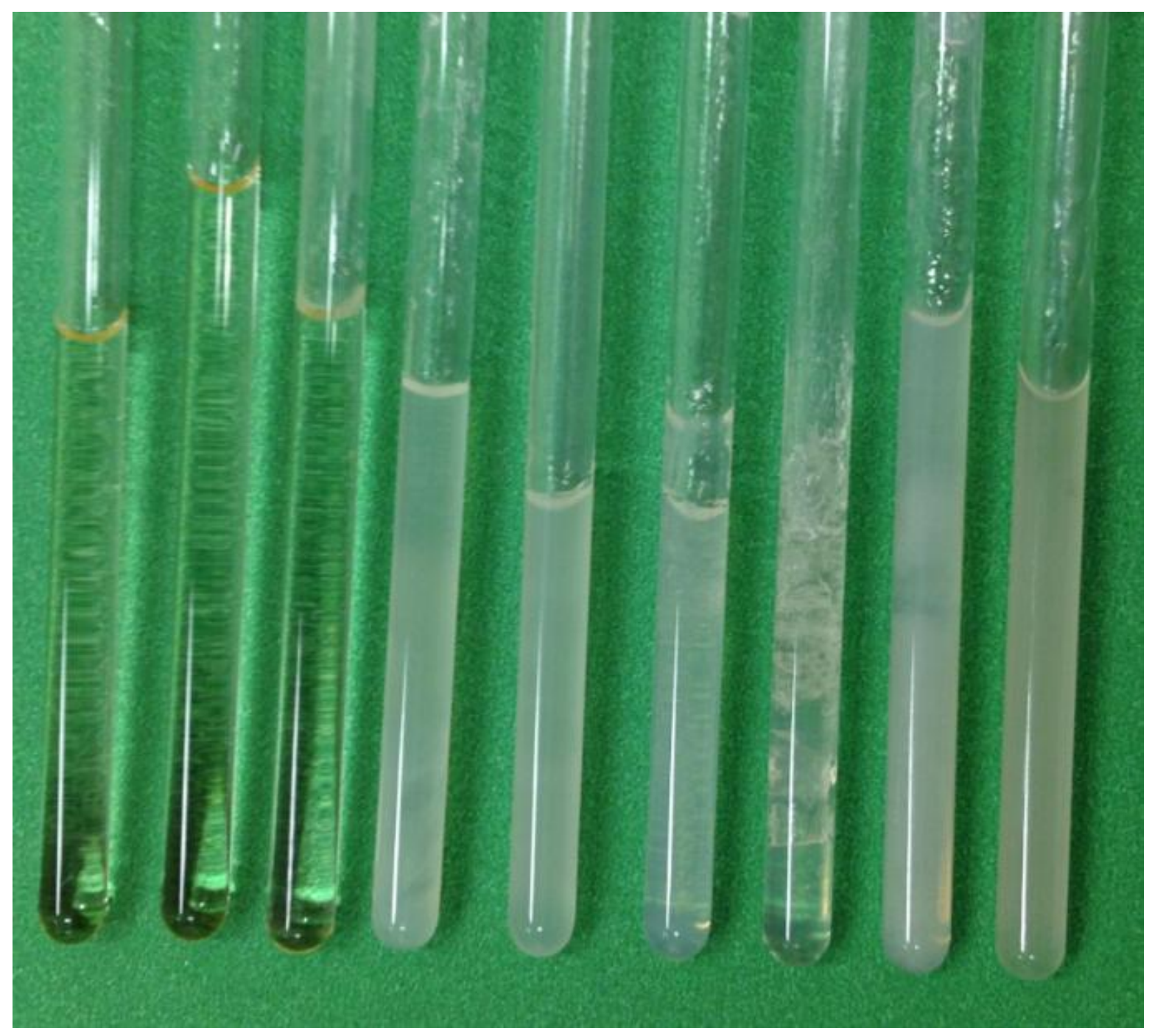

Figure S1. Sample morphology of LiTFSI and [DMIm][MPEG ${ }_{200} \mathrm{Pi}$ ] mixture as a function of LiTFSI molar ratio (x). The LiTFSI molar ratio $\mathrm{x}=0,0.1,0.3,0.4,0.5,0.6,0.8,1.0$, and 3.0 from left to right. 

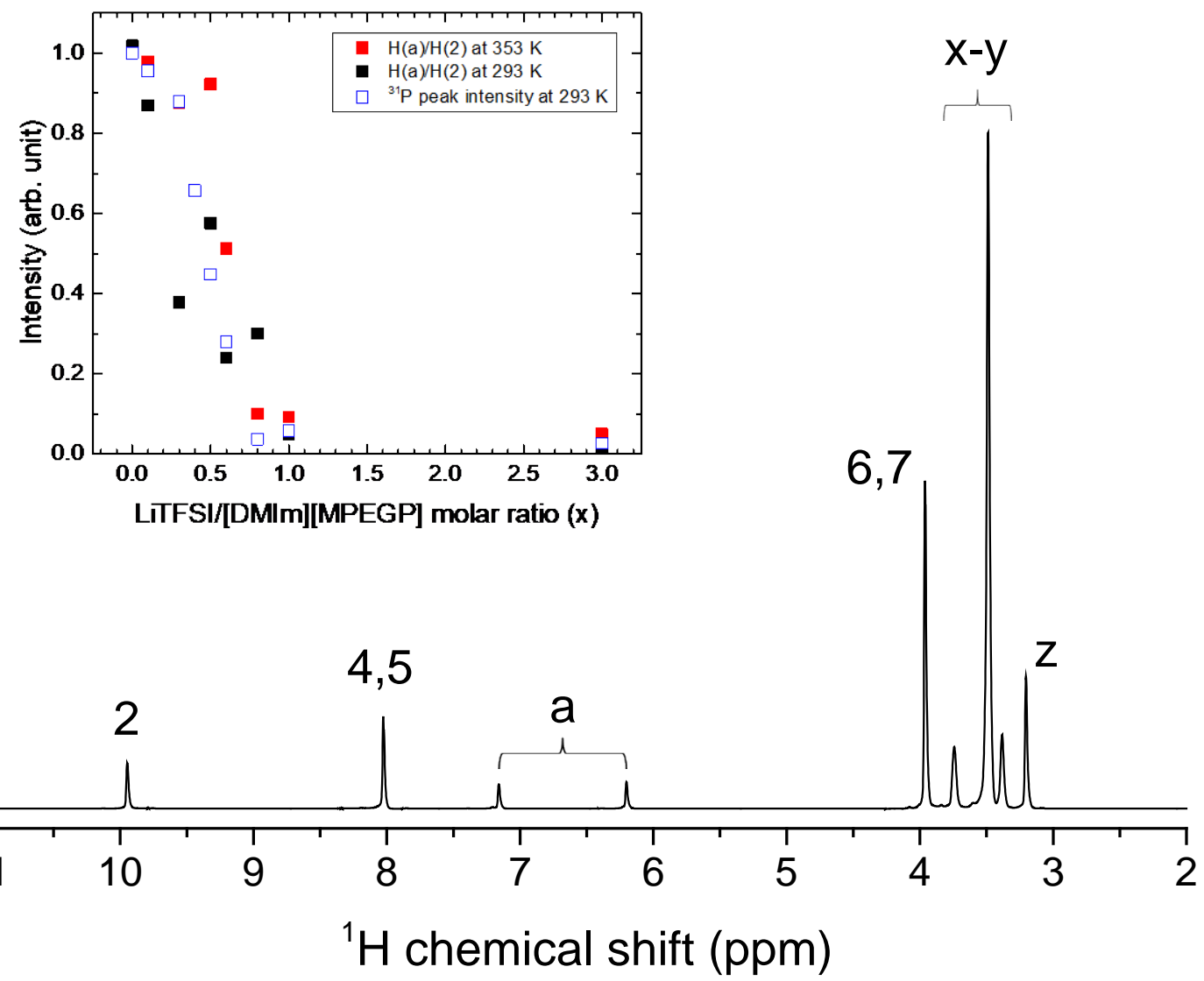

Figure S2. ${ }^{1} \mathrm{H}$ NMR spectrum of neat [DMIm][MPEGP] obtained at $353 \mathrm{~K}$. Inset is the intensity ratio of $\mathrm{H}(\mathrm{a}) / \mathrm{H}(2)$ obtained at 293 and $353 \mathrm{~K}$ and the ${ }^{31} \mathrm{P}$ peak intensity at $293 \mathrm{~K}$ as a function of LiTFSI content. The peaks correspond to the numbering on the chemical structure, see Scheme 1. 


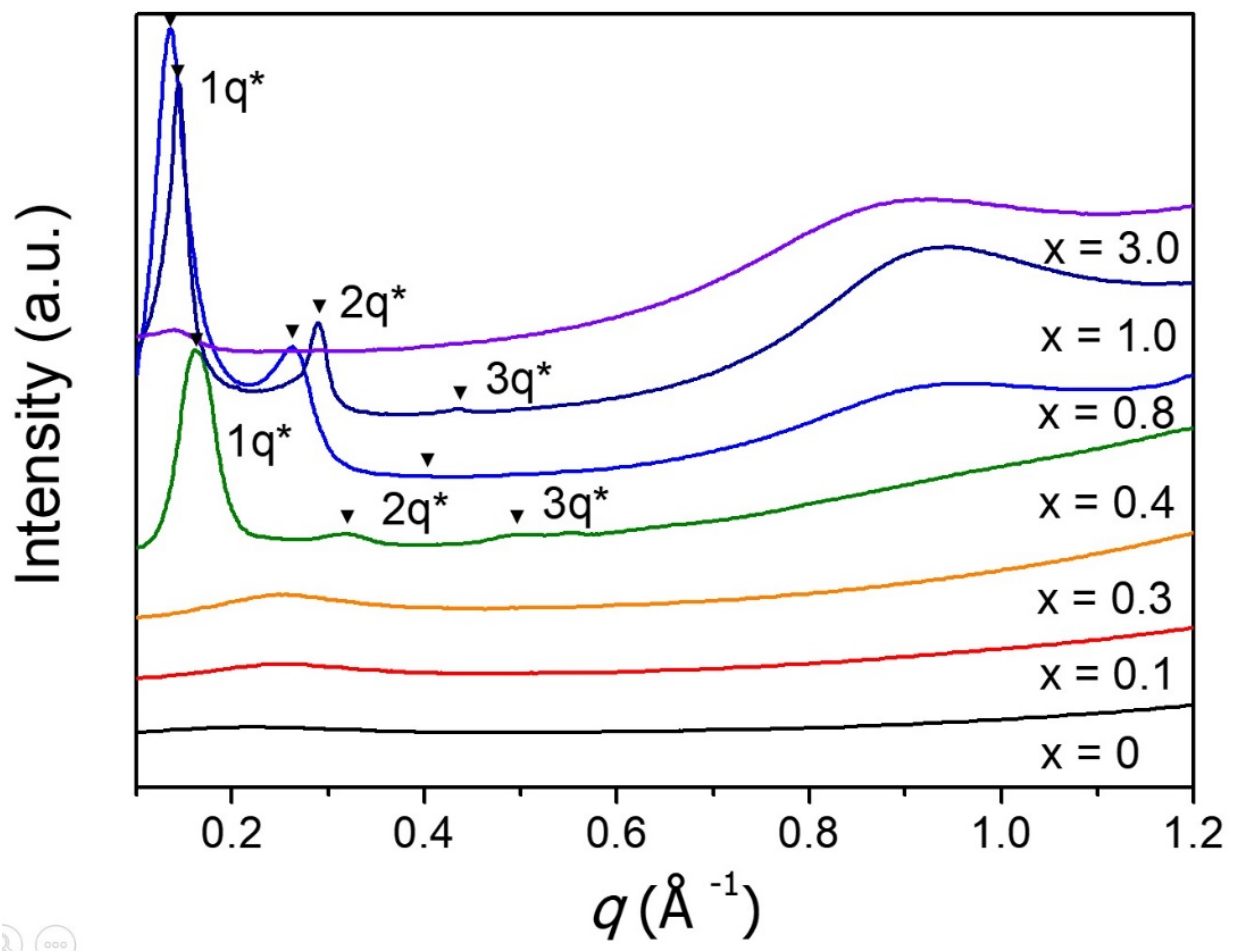

Figure S3. SAXS curves of ionic mixtures at various salt contents at room temperature. 


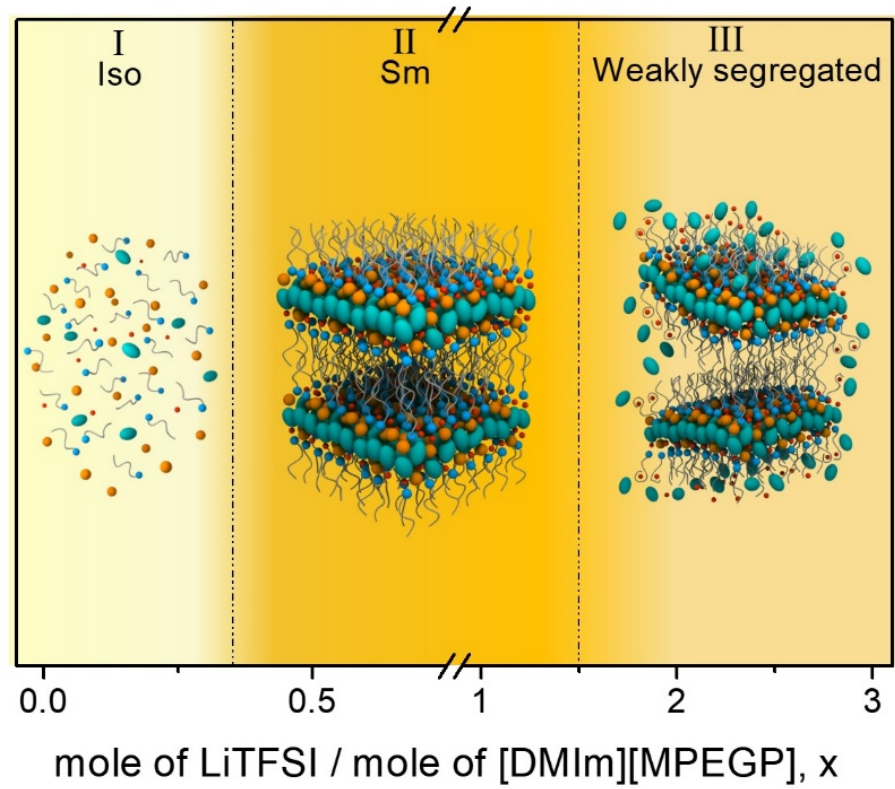

Figure S4. Phase diagram and schematic illustration of the mesostructure for [DMIm][MPEGP] and LiTFSI mixtures as a function of relative salt content at room temperature. 
(a)

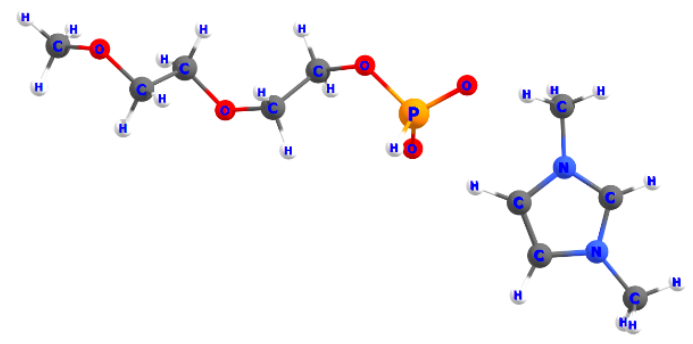

\section{[DMIm][MPEGP]}

$\delta\left({ }^{31} \mathrm{P}\right)=1.571 \mathrm{ppm}$

$J_{\mathrm{PH}}=571.63 \mathrm{~Hz}$

(b)

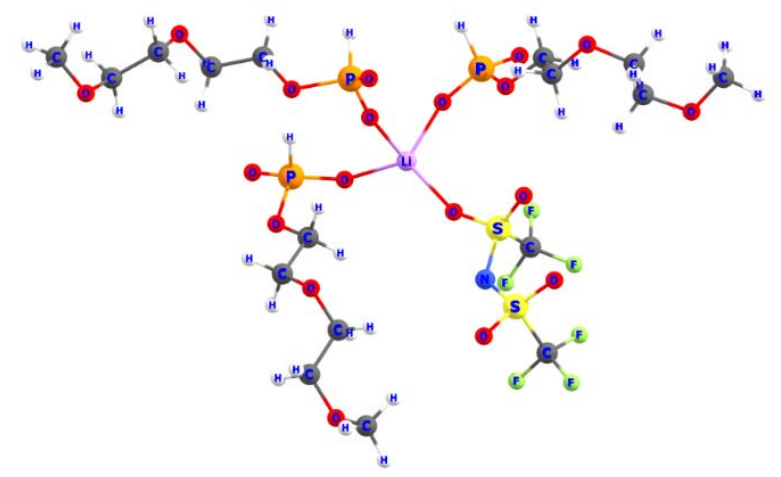

\section{Li-[MPEGP] $]_{3}$-TFSI}

$\delta\left({ }^{31} \mathrm{P}\right)=8.001 \mathrm{ppm}$

$J_{\mathrm{PH}}=575 \mathrm{~Hz}$

(c)

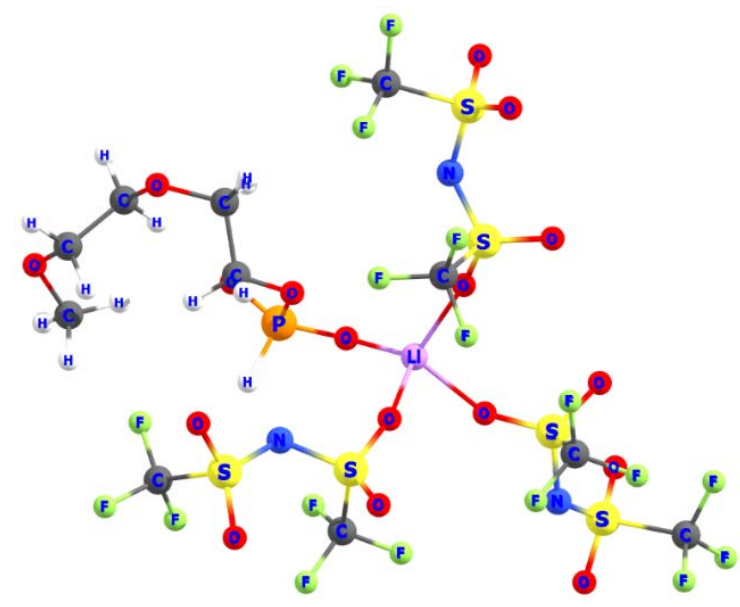

Li-[MPEGP]-TFSI3

$\delta\left({ }^{31} \mathrm{P}\right)=-7.879 \mathrm{ppm}$

$J_{\mathrm{PH}}=584.14 \mathrm{~Hz}$ (d)

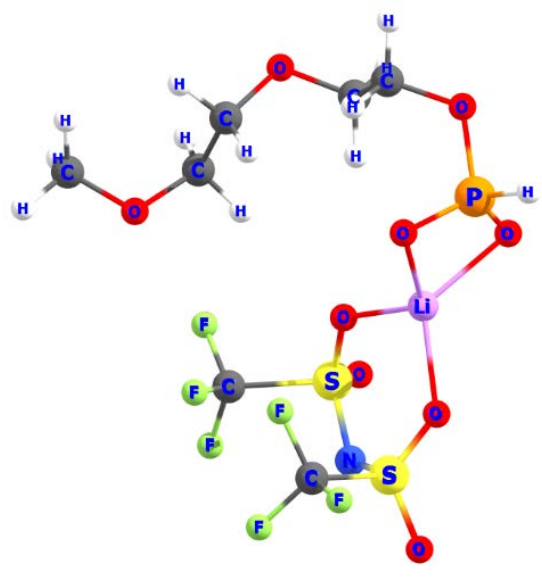

Li-[MPEGP]-TFSI

$$
\begin{aligned}
& \delta\left({ }^{31} \mathrm{P}\right)=-11.179 \mathrm{ppm} \\
& J_{\mathrm{PH}}=596.52 \mathrm{~Hz}
\end{aligned}
$$

Figure S5. Theoretically predicted $\delta\left({ }^{31} \mathrm{P}\right)$ and $J_{\mathrm{PH}}$ of ${ }^{31} \mathrm{P}$ NMR for [MPEGP] ${ }^{-}$anions in several solvation structures of (a) pure [DMIm][MPEGP], (b) Li-[MPEGP] 3 -TFSI, (c) Li-[MPEGP]-TFSI3 and (d) Li-[MPEGP]-TFSI. 


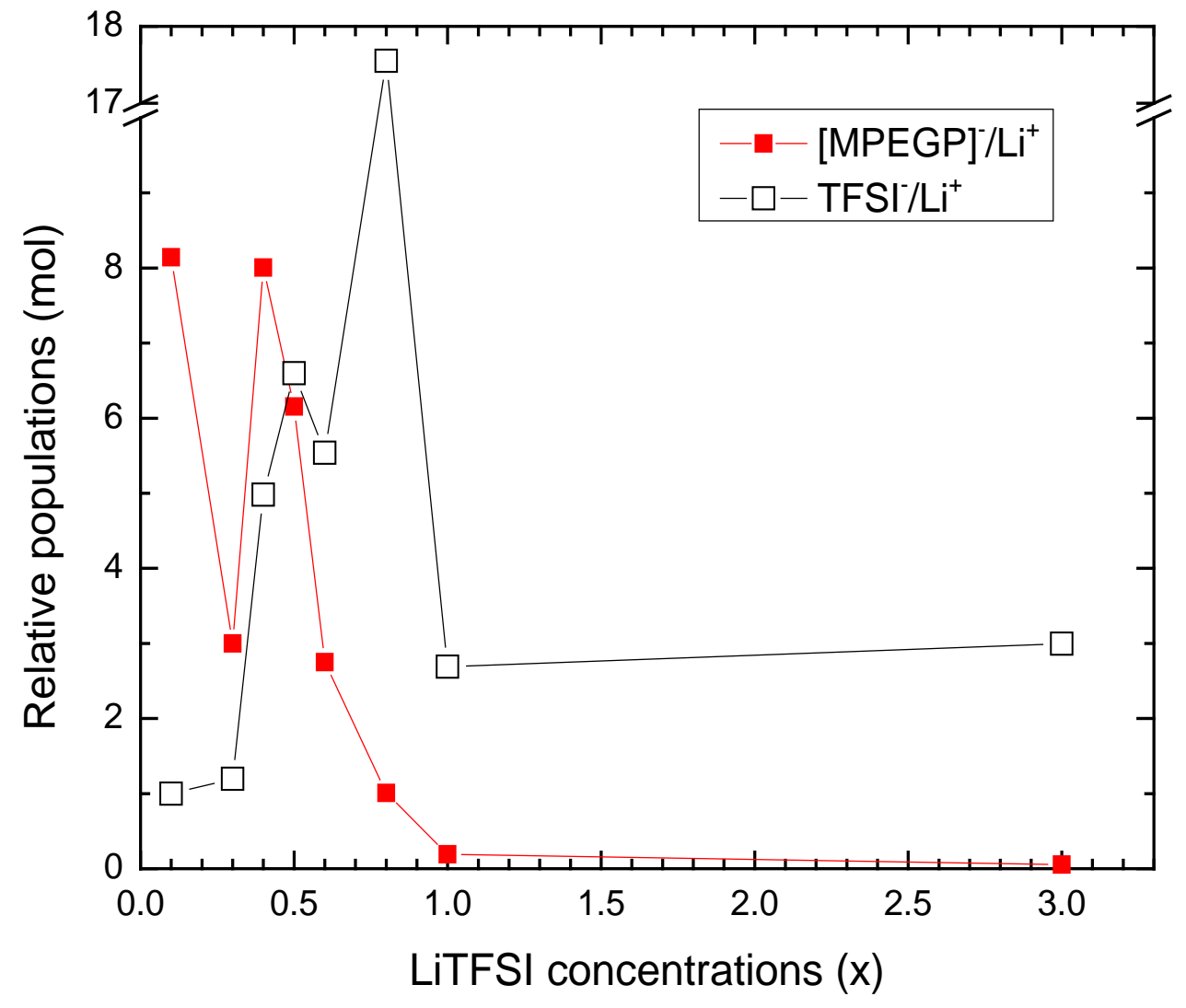

Figure S6. The number ratio of mobile [MPEGP] ${ }^{-}$anions to $\mathrm{Li}^{+}$cations as a function of LiTFSI relative content. 

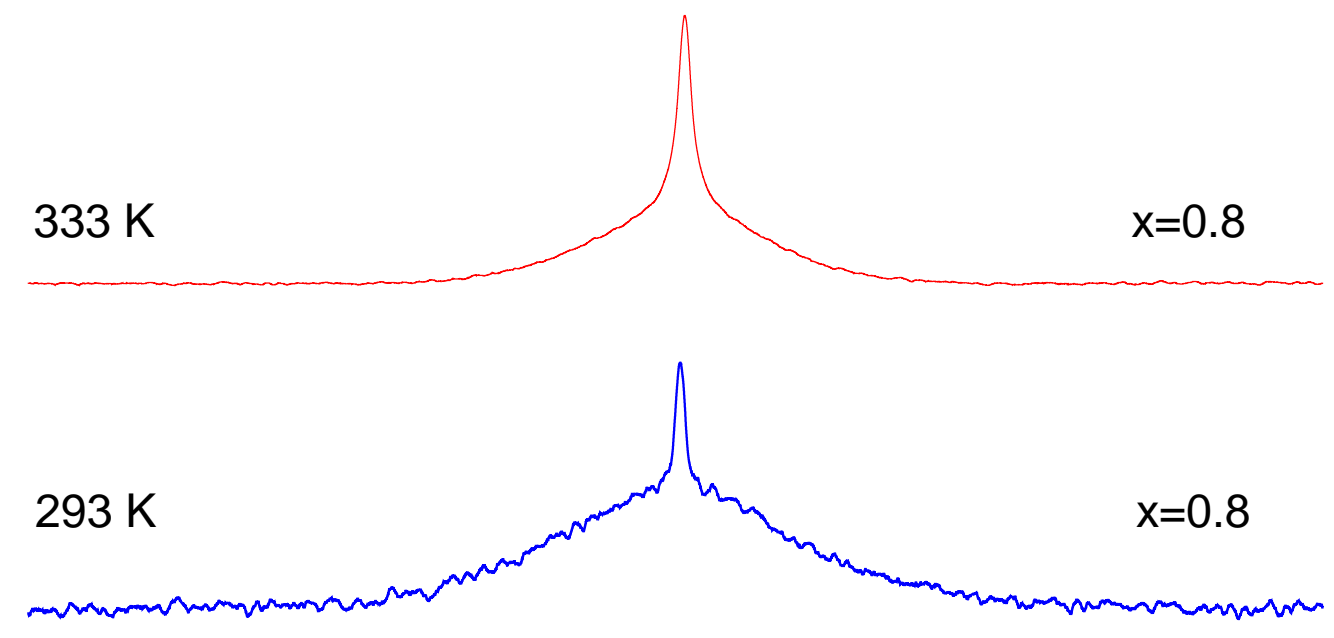

\begin{tabular}{|c|c|c|c|c|c|c|c|c|}
\hline 80 & 60 & 40 & 20 & 0 & -20 & -40 & -60 & -80 \\
\hline
\end{tabular}

Figure S7. ${ }^{7} \mathrm{Li}$ NMR spectrum of $\mathrm{x}=0.8$ sample at 293 and $353 \mathrm{~K}$. 


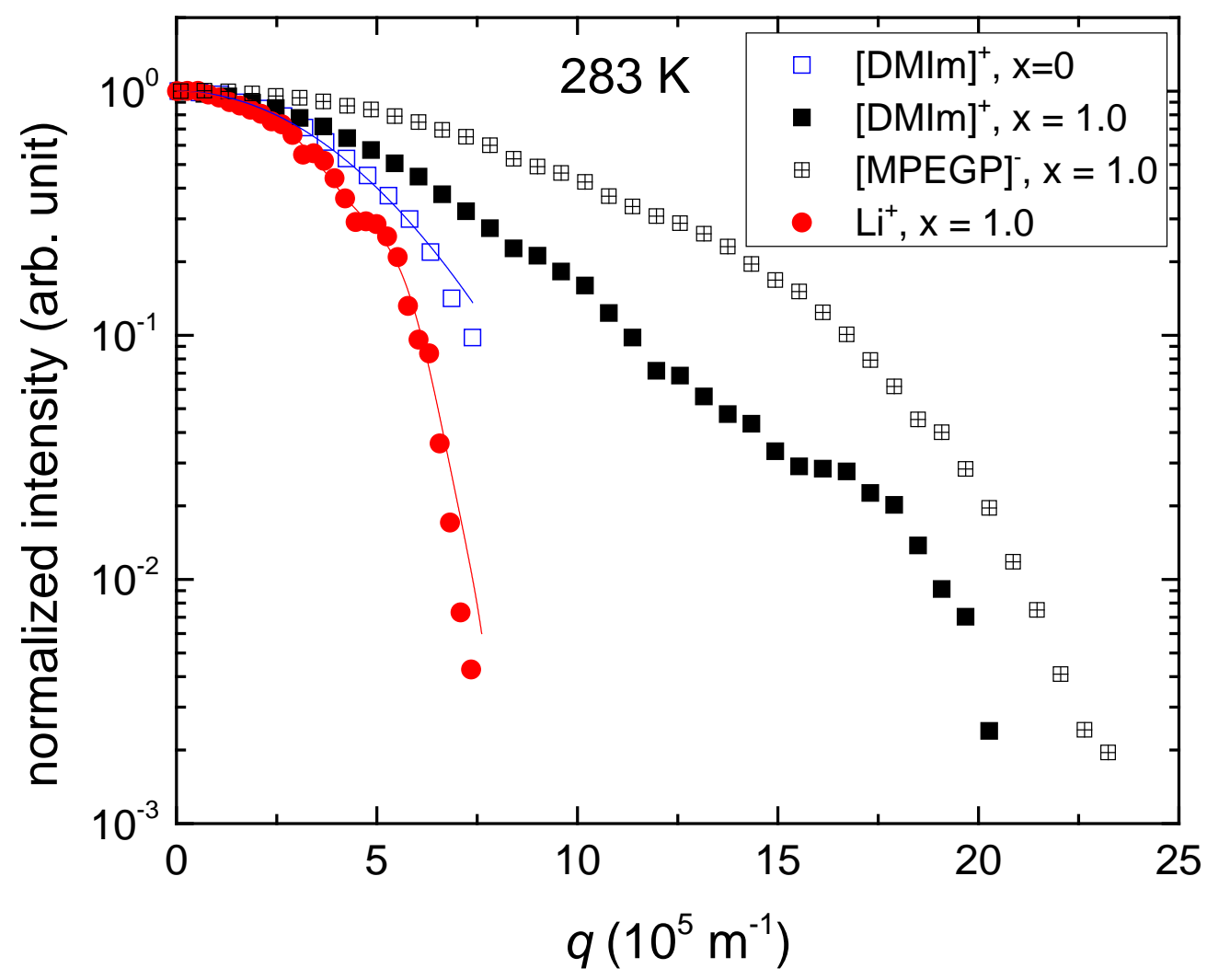

Figure S8. ${ }^{1} \mathrm{H}$ PFG-echo profile obtained for $[\mathrm{DMIm}]^{+}$cation in pure [DMIM][MPEGP] $(\mathrm{x}=0)$ and ${ }^{1} \mathrm{H}$ and ${ }^{7} \mathrm{Li}$ PFGecho profiles in the mixture of LiTFSI and [DMIm][MPEGP] at $\mathrm{x}=1.0$ at $283 \mathrm{~K}$. 


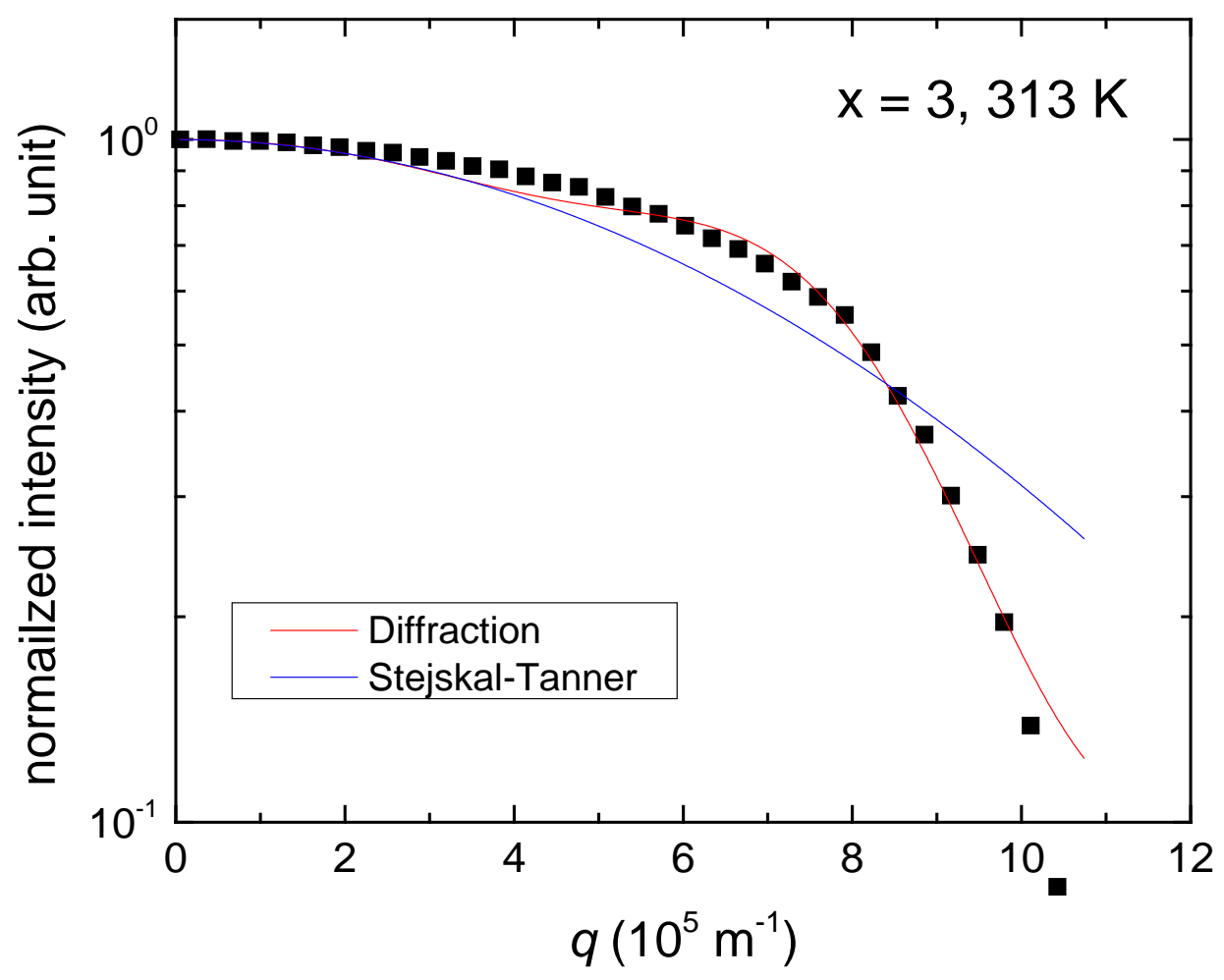

Figure S9. ${ }^{7} \mathrm{Li}$ PFG-NMR echo decay in the mixture of LiTFSI and [DMIm] [MPEG $\left.{ }_{200} \mathrm{Pi}\right]$ at $\mathrm{x}=1.0$ as a function of diffusion time, $\Delta$ at the temperatures of 293 (a) and $333 \mathrm{~K}$ (b). 
(a)

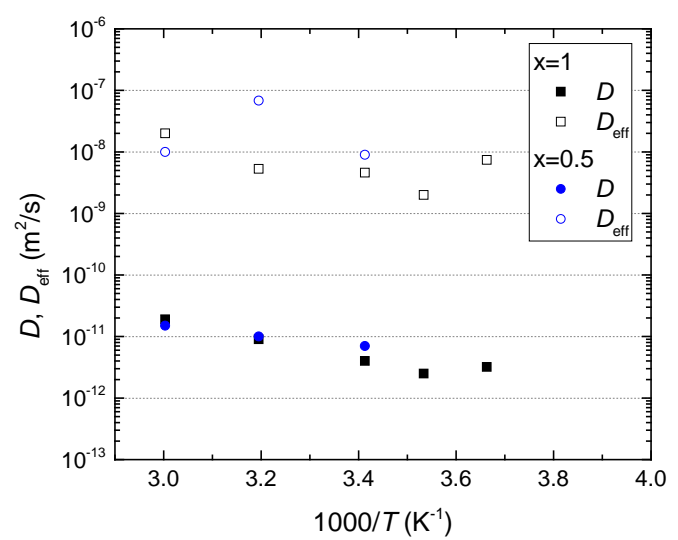

(b)

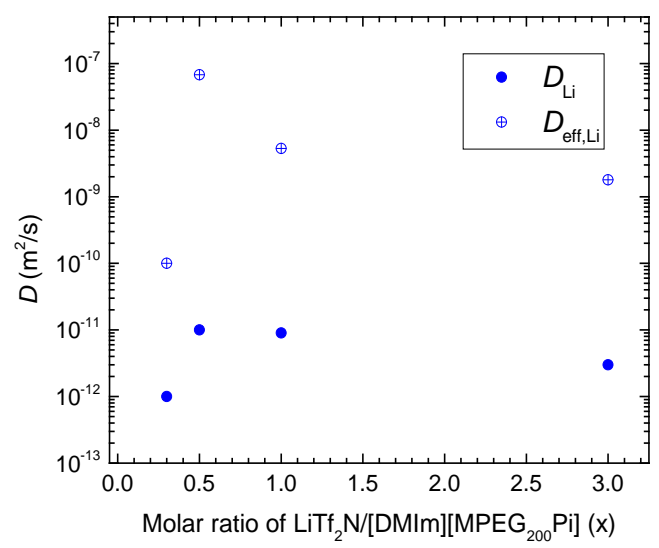

Figure S10. (a) $D_{\text {eff }}$ of $\mathrm{Li}^{+}$cation as a function of temperature obtained from the ${ }^{7} \mathrm{Li}$ PFG-NMR echo profile using NMR diffraction equation at LiTFSI molar contents of $x=0.5$ and 1 . It shows three orders of magnitude faster than $D$ obtained using Stejskal-Tanner equation. (b) $D$ and $D_{\text {eff }}$ obtained from ${ }^{7}$ Li PFG-echo profiles at $\mathrm{x}=0.3,0.5,1$, and 3 at $313 \mathrm{~K}$. 